\section{Minutes of Medanta Neurocritical Care Conference 2014}

\section{Saurabh Anand, Harsh Sapra ${ }^{1}$}

The Medanta Neurocritical Care Conference, 2014 was held on 26 April 2014 at Medanta, the medicity hospital Gurgaon. It was organised jointly by the Department of Neurosciences and the Department of Anaesthesia and Critical Care under the able leadership of Dr. Harsh Sapra (organising chairman) and Dr. Saurabh Anand (organising secretary). The registration began at 8:15 am. The conference was formally inaugurated at 9:00 am, by Dr. Yatin Mehta (Chairman Anaesthesia and Critical Care, Medanta) and Dr. AN Jha (Chairman of Neurosciences, Medanta) with lamp lighting and a welcome speech by Dr. AN Jha where he emphasised on monitoring in neurocritical care. This academic feast was attended by 150 delegates from all over India. The conference started with the session on 'Trauma' which included three lectures. The first was delivered by Dr. Kavita Sandhu (Delhi) on 'Critical care management of cervical spine' followed by 'Monitoring directed management of head injury' and 'Surgical decompression in head injury and stroke patients' by Dr. Rajiv Chawla (Delhi) and Dr. Karanjit Narang (Gurgaon), respectively. After a short tea break, there was a session on 'Subarachnoid Haemorrhage' which included three lectures. Dr. Peter Farling (UK) delivered a talk on 'Metabolic derangements monitoring and treatment' followed by Dr. Saurabh Anand (Gurgaon, organising secretary) and Dr. Gaurav Goel (Gurgaon) who talked about the 'Medical and Endovascular management of delayed cerebral ischemia', respectively. Before the third session, there was an address by the chief patron and Chairman and Managing Director of the Medanta hospital, Dr. Naresh Trehan, and he emphasised on the importance of good 'relation between surgeon and critical care team'. The third session was on 'Homeostasis' which began with the talk on 'Hypothermia: When and how to cool' by Dr. Umamaheswara Rao (Banglore). In the same session, Dr. Hemant Bhagat (Chandigarh) spoke about 'Hyponatremia' and Dr. Girija P Rath (Delhi) spoke on 'Management of potential organ donor in ICU'. This session was followed by lunch. Post lunch, first session was on 'Neurological Emergency' which started with lecture on 'Emergency management of stroke' by Dr. Kapil Zirpe (Pune). The other two topics covered in this session were on 'Critical care management of $\mathrm{ICH}^{\prime}$ and 'Critical care management of status epilepticus guidelines and beyond' taken by Dr. Pravin Amin (Mumbai) and Dr. Shashi Srivastava (Lucknow), respectively. We didn't ignore the importance of infection in intensive care unit (ICU) as the evening session addressed this issue with two lectures. The first one was on 'Biochemical marker of sepsis' by Dr. Jaya Wanchoo (Gurgaon) and the other one was on 'Aseptic meningitis and role of intrathecal antibiotics' taken by Dr. Neha Gupta (Gurgaon). Every session was followed with a 15-minute discussion. This was followed by a short tea break.

The conference ended with a panel discussion on 'Brain Death and end of life issues'. Dr. Yatin Mehta (Gurgaon) moderated panellists, Dr. Virendra Jain (Gurgaon), Dr. L.D Mishra (Varanasi), Dr. S.S Saini (Gurgaon) and Dr. Tariq (Gurgaon). The conference concluded with vote of thanks given by Dr. Harsh Sapra to all the speakers and his whole team (organising chairman) with a promise that this will be an annual event.

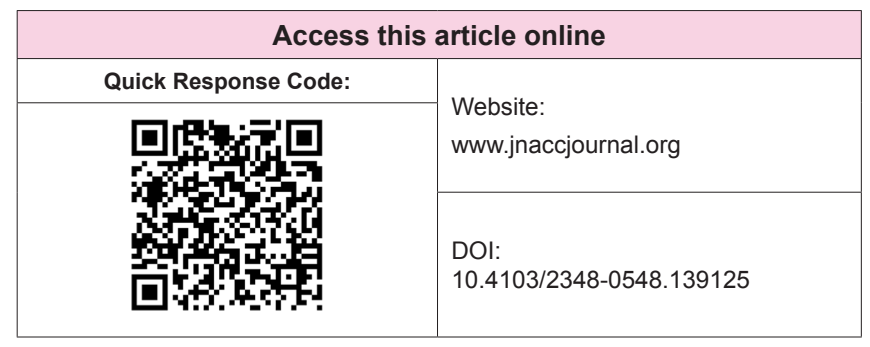

Consultant, ${ }^{1}$ Associate Director, Medanta, The Medicity, Gurgaon, Haryana, India 